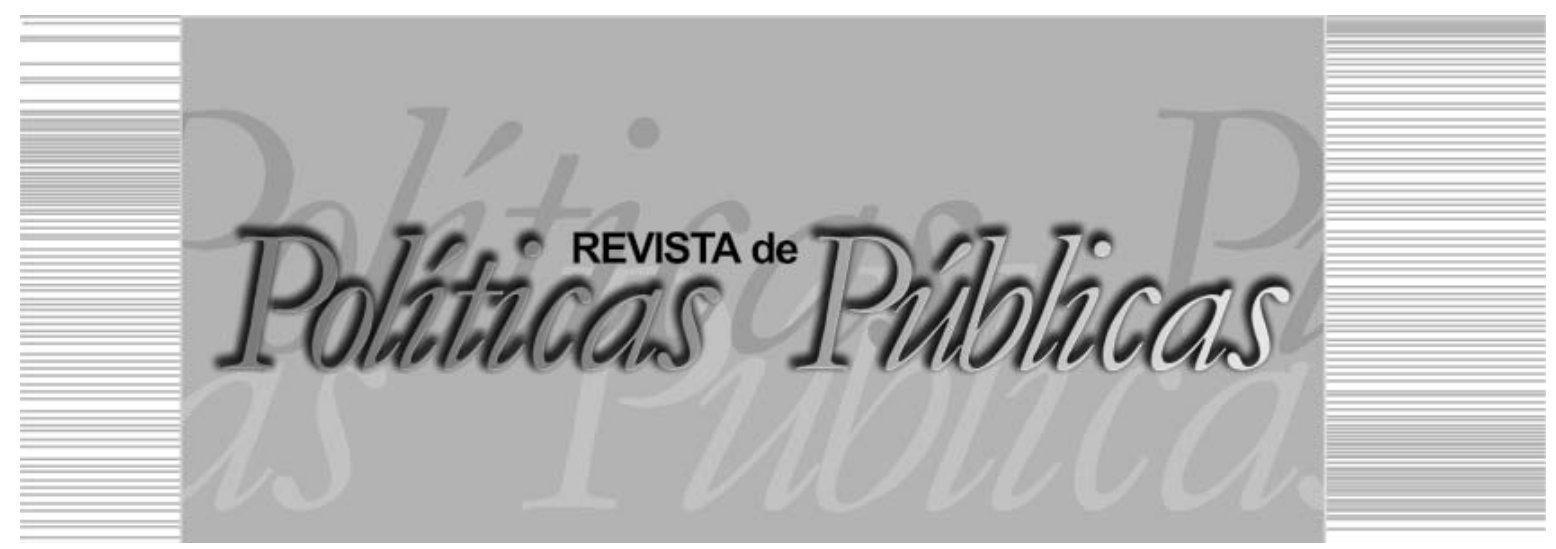

\title{
TENDÊNCIAS E IMPASSES DA SEGURIDADE SOCIAL E O FUTURO DA PREVIDÊNCIA NO BRASIL CONTEMPORÂNEO
}

\author{
Evania Oliveira Severiano ${ }^{1}$ \\ Instituto Nacional do Seguro Social (INSS) \\ Faculdade Metropolitana da Grande Fortaleza (FAMETRO)
}

\section{Resumo}

$\mathrm{O}$ artigo analisa tendências e impasses da Seguridade Social e da Previdência Social no contexto das contrarreformas no Brasil contemporâneo. Tem por base pesquisa bibliográfica, documental e observação militante. Enfatiza que, no âmbito das contrarreformas, aprofunda-se a precarização dos direitos sociais, sob duplo movimento sincronizado: mercantilização de direitos, sobretudo na saúde, previdência, educação e acesso seletivo e focalização em ações referidas à Política de Assistência Social. Conclui que entre as múltiplas determinações desses processos, sob a hegemonia da financeirização da riqueza, destacam-se, no Brasil, três processos articulados: confluência entre as conquistas democráticas e direitos sociais na Constituição/1988; ciclos de ajustes e contrarreformas e mais recentemente o fenômeno denominado "golpe parlamentar-jurídico e midiático".

Palavras-chave: Estado, Fundo Público, Seguridade e Previdência Social, direito social.

\footnotetext{
Assistente Social. Doutora em Sociologia. Assistente Social no Instituto Nacional do Seguro Social (INSS) e Professora do Departamento de Serviço Social na Faculdade Metropolitana da Grande Fortaleza (FAMETRO). E-mail: evaniaseveriano@gmail.com Instituto Nacional do Seguro Social - INSS | Rua Pedro Pereira, 383, Centro, Fortaleza/CE | CEP: 60.035-000 | Faculdade Metropolitana da Grande Fortaleza - FAMETRO | Campus Conselheiro Estelita | Rua Conselheiro Estelita No 500 - Centro, Fortaleza/CE | CEP: $60010-260$
} 


\title{
TRENDS AND IMPASSES OF SOCIAL SECURITY AND THE FUTURE OF THE PREVIDENCE IN CONTEMPORARY BRAZIL
}

\begin{abstract}
This article proposes to analyze trends and impasses of social security and social previdence in the context of counterreforms in contemporary Brazil. It intends to share interpretations woven in the doctoral thesis and recent project of scientific initiation. Study of a qualitative nature using bibliographical research; Documentary and observation in professional, militant and academic intervention. As main results we summarize: the Brazilian security transformed into an object of counter-reforms deepens the precariousness of social rights, under a double synchronized movement of commercialization of rights, especially in health, social security, education and selective access and focused on social assistance policy. There are multiple determinations and requires deciphering reciprocal relations of capitalism under the hegemony of the financialization of wealth, and in Brazil, three articulated processes: confluence between the democratic achievements and social rights in the Constitution/1988; Cycles of adjustments and counter-reforms to the order of the financialized capital, and the most recent phenomenon called "parliamentary-legal and mediatic coup" in the context of the democracy in question.

Key words: State, Public Fund, Social Security and Social Previdence, social law.
\end{abstract}

\section{INTRODUÇÃO}

A universalização da Seguridade constituída pelas políticas de saúde, assistência social e previdência social torna-se pilar essencial na proteção social brasileira, fruto da cidadania ativa a seguridade, portanto, materializa direitos sociais que possuem um potencial estratégico no enfrentamento da desigualdade social. A compreensão do significado da seguridade pressupõe contextualizá-la na dinâmica da sociedade, da qual é parte e expressão. Nesse cenário, presentes estão os projetos societários em disputa e sujeitos de direitos/ atores sociais com posições diferenciadas nas relações econômicas, políticas, culturais e sociais. A arquitetura da seguridade e de suas políticas constitutivas (saúde, previdência e assistência) da forma como instituída no Titulo VIII da Constituição Federal (CF) de 1988, segue tendências/impasses de estruturação e contrarreformas.

Corroboramos a defesa do Conjunto Conselho Federal de Serviço Social (CFESS)/Conselho Regional de Serviço Social (CRESS) 
ao defender o conceito mais amplo de seguridade social, que incorpore outros direitos e políticas sociais, constituindo um verdadeiro padrão de proteção social no Brasil (CONSELHO FEDERAL DE SERVIÇO SOCIAL, 2000). Nesse caso incorporando da CF/1988 o Capitulo $6^{\circ}$ (Dos direitos sociais)- Título II- Dos direitos e garantias fundamentais. Informa esse artigo: "São direitos sociais a educação, a saúde, a alimentação, o trabalho, a moradia, o transporte, o lazer, a segurança, a previdência social, a proteção à maternidade e à infância, a assistência aos desamparados, na forma desta Constituição." (BRASIL, 2002).

Todavia, são enormes os impasses da seguridade e previdência social no contexto das contrarreformas no Brasil contemporâneo, sendo afetadas por movimentos que estão sintonizados com projetos políticos societários, seguindo diretrizes liberais-conservadoras, reformistas e neoliberais e que expressam orientações quanto ao modelo do Estado, interferindo em decisões, prioridades, planos, programas e projetos governamentais que materializam direitos e políticas sociais no contexto da regulação social no capitalismo. (SEVERIANO, 2012).

Pretendemos analisar e compreender as tendências da política de seguridade social sobre o futuro da Previdência Social no contexto do Brasil contemporâneo, ressaltar a complexa conjuntura de 2016, com o afastamento abrupto da Presidenta eleita Dilma Rousseff (Partido dos Trabalhadores [PT]), assumindo em seu lugar, o seu vice, Michel Temer, com uma programática expressa no documento Uma ponte para o futuro, lançado pelo seu partido, o Partido do Movimento Democrático Brasileiro (PMDB) em 2015. Já se tem consenso em várias análises que o Brasil vive um golpe jurídico, político e midiático. Até em análises como a do economista e cientista político que foi Ministro no Governo Fernando Henrique Cardoso (FHC), Luiz Carlos Bresser Pereira, em entrevista, entende que o impedimento da Presidenta Dilma constituiu um golpe de Estado e, portanto, um atentado contra a Constituição brasileira. Ressaltou como razões fundamentais para esse cenário brasileiro a crise do ciclo de democracia e justiça social iniciado em 1980, e o que nos ameaça no lugar disso, é um retrocesso com a força do renascer neoliberal ortodoxo, trazendo graves riscos de redução do Brasil a uma condição de colônia dos grandes países, com a associação de interesses entre as elites locais e as elites internacionais. (MAGALHÃES, 2016). 
Desenvolveremos a analise sob três eixos estruturantes: no primeiro eixo procuramos traçar as configurações contemporâneas do Estado, proteção social e fundo público sob o atual estágio do capitalismo e as consequentes mudanças societárias e tendências da seguridade social sob as complexas tramas da modernidade contemporânea. O segundo eixo de análise pretende apreender as complexas mediações e particularidades dos impasses e tendências da seguridade social brasileira, destacando momentos da estruturação e contrarreformas, contexto especial de presença dos processos de mercantilização invadindo certos direitos sociais e impactando a proteção social no Brasil. No terceiro eixo, daremos destaque para a Previdência Social, enquanto política de seguridade, um direito social, evidenciando as contrarreformas operadas no Brasil contemporâneo, com especial realce para as severas propostas de contrarreformas que visam restringir e precarizar os direitos sociais previdenciários que, sendo aprovadas, afetará tanto o Regime Geral como o Regime Jurídico dos servidores públicos.

Do ponto de vista do caminho metodológico da investigação, optamos pela abordagem qualitativa para desenvolver a compreensão do fenômeno em sua existência, forma e complexidade (BECKER, 2007). Fizemos uso de pesquisas bibliográfica e documental com observação na intervenção profissional, militante e acadêmica, o que gerou motivações para compartilharmos interpretações tecidas durante a tessitura da tese de doutoramento e, mais recente, adensadas pelo desenvolvimento do projeto de iniciação cientifica privilegiando essa temática. Foram ricas as oportunidades de reflexões desenvolvidas no espaço de encontros com discente/iniciante cientifico, bem como, orientandas de monografias com temas e interesses relacionados. Com a produção deste artigo, socializamos a síntese dessa construção coletiva nesses espaços, visando contribuir com a produção de conhecimento dessa importante temática às políticas públicas e para o exercício profissional. Tendo a compreensão das complexas e ricas determinações envolvidas, da fundamental importância das aproximações sucessivas, esperamos adensar interpretações e reflexões sobre as configurações contemporâneas da conjuntura brasileira e os rebatimentos nas políticas de seguridade social, nos direitos dessas políticas e no futuro da Previdência Social brasileira. 


\section{ESTADO, PROTEÇ̃̃O SOCIAL E FUNDO PÚBLICO:} movimentos de estruturação e tendências no capitalismo sob a finança mundializada

A análise do Estado e da proteção social como base para compreender o sistema de seguridade e previdência exige a abordagem em sua totalidade, considerando a história e as contradições associadas aos múltiplos fenômenos que se apresentam na sociedade capitalista e suas determinações. Nesse primeiro eixo de análise centralizamos a discussão do Estado, proteção social e fundo público, destacando marcos de estruturação da seguridade social e peculiares processos sob o atual estágio do capitalismo com consequentes mudanças societárias que nos lançam em tempos difíceis no mundo e no Brasil.

A associação entre a mundialização do capital e o neoliberalismo provoca um cenário de múltiplas crises nas esferas, econômica, política, ambiental, social e cultural. Somos desafiados a decifrar os acontecimentos, identificar causas e consequências e, á luz do conhecimento, é possível transformar os impasses em lutas que organizem, mobilizem a sociedade para intervir na construção de um futuro emancipatório para a humanidade.

Foi no século XIX, no contexto das contradições e crises cíclicas que marcam a história do capitalismo, que registramos os primeiros pactos entre o capital e trabalho influenciando os fundamentos/organização do Estado (liberal) com a emergência da sociedade moderna e as profundas transformações sociais, políticas e econômicas. Na Alemanha, com as políticas sociais de Bismarck em 1883 , registramos a primeira norma previdenciária do mundo a instituir um seguro obrigatório, com a participação do Estado e custeio tríplice. Há outros marcos importantes, todavia, foi na passagem do Estado liberal ao Estado Social no primeiro quartel do século XX, ante a mais uma das severas crises do capitalismo com diversas repercussões, que favoreceu e aprofundou o movimento de estruturação das políticas de proteção e da seguridade social, no contexto do capitalismo monopolista, no segundo pós-guerra. Destacamos nesse contexto a Declaração Universal dos Direitos do Homem, de1948, que elevou a proteção social como um direito fundamental. Todavia, podemos afirmar que os modelos Bismarkiano e Beveridgiano influenciarão os processos de organização e estruturação da Seguridade e Previdência no Brasil e no mundo. O Primeiro, mais depen- 
dente do mercado de trabalho, desenvolvido na Alemanha a partir de 1883, sob a influência de Otto Bismarck, apresenta um conceito de segurança social restrito à lógica do seguro, caracterizado pela contribuição individual como critério para aferimento dos benefícios/ direitos. Já o segundo, Plano Beveridge de Seguridade Social foi publicado em 1943, na Inglaterra, por William Beveridge, no contexto do capitalismo monopolista, imperando o esquema keynesiano/fordista, no segundo pós-guerra e de mobilização e organização da classe trabalhadora. O Plano Beveridge é considerado o marco importante para o conceito contemporâneo de seguridade social e caracteriza-se por ser um modelo menos dependente do mercado de trabalho, oposto à razão do seguro, universalista, no qual a proteção social seria definida pela condição de cidadania de cada indivíduo. Seguindo Boschetti (2006), em que pesem as particularidades na construção da seguridade no Brasil, seguimos uma tendência de hibridização com o modelo bismarckiano ainda orientando a estrutura da previdência social, enquanto o modelo beverigiano, orientando os princípios da saúde e da assistência social.

Ocorre que, nesse período entre as décadas de 1940 e 1970, nos chamados 30 anos gloriosos, o fundo público ganha centralidade na produção e regulação das condições econômicas e sociais, fundamental para a reprodução do capital. Segundo Oliveira (1998), é simultânea a dupla operação de presença do fundo público na reprodução da força de trabalho e do capital. Ressalta que a formação do sistema capitalista é impensável sem a utilização dos recursos públicos. Assim, a formação da taxa de lucro passa pela mediação do fundo público, componente estrutural insubstituível.

Todavia, após a década de 1970, ante a mais uma das severas crises estruturais do capitalismo, com complexas mudanças, o esquema keynesiano/fordista tende a perder a sua capacidade paradigmática, dando lugar à finança mundializada do capital associado ao neoliberalismo. Nesse contexto, as principais transformações se caracterizam pela passagem de um regime de acumulação centrado na esfera da produção, para uma acumulação de dominância financeira com alterações nas relações do fundo público, com a reprodução do capital e da força de trabalho. Ou seja, são processos que reestruturam a economia mundial em múltiplas dimensões, com exponencial avanço na tendência de internacionalização da produção e dos mercados, reestruturam o Estado e traz novas configurações para a disputa e lógica do fundo público, processos que irão aprofundar de- 
sigualdades entre as nações, classes e grupos sociais. (CHESNAIS, 2005). Nesse contexto, teremos o campo fértil para as repetidas contrarreformas restritivas dos direitos sociais com forte tendência de precarização das políticas de proteção social, sobretudo na área da seguridade social.

No centro das relações econômicas e sociais, no período contemporâneo, está o capital portador de juros e o capital fictício que utiliza o empreendimento do endividamento, sobretudo estatal e da mercantilização na esfera dos direitos sociais, fontes geradoras de lucro e acumulação, reproduzindo o grande capital com repercussões nas relações com o fundo público, cuja maior expressão é o orçamento público. Uma das principais formas de constituição do fundo público ocorre por meio da extração de recursos da sociedade na forma de: impostos, contribuições e taxas, sendo o resultado, portanto, da tributação das diversas formas de renda da economia: salário, lucro, juro e renda da terra. Esses recursos são apropriados pelo Estado para o desempenho de múltiplas funções. Atualmente, o fundo público exerce pelo menos, quatro importantes funções no capitalismo: O financiamento do investimento capitalista, por meio de subsídios, desonerações tributárias, incentivos fiscais; a garantia de um conjunto de políticas sociais que asseguram direitos e permitem também a inserção das pessoas no mercado de consumo, independentemente da inserção no mercado de trabalho; Assegura vultosos recursos do orçamento para investimentos em meios de transporte e infraestrutura, e ainda, assegura renda para uma classe rentista na sociedade, isto é, aqueles que vivem de aplicações no mercado financeiro e recebem, por meio do orçamento público, recursos sob a forma de juros e amortização da dívida pública. (SALVADOR; SILVA, 2015).

A mundialização do capital, ao situar o financeiro no comando da economia, repercutirá em quase todas as determinações da vida social, no modo de repartição da riqueza social, bem como nas formas do emprego assalariado. Nesse cenário, as principais instituições envolvidas compreendem os bancos, as companhias de seguro, os fundos de aposentadoria por capitalização - os fundos de pensão. A financeirização, frequentemente redunda em estagnação da produção material e destruição do aparato produtivo, que na periferia do capitalismo assume os tons mais dramáticos, desemprego e precarização do emprego. (CHESNAIS, 2005). O triunfo atual do mercado com autonomização do capital-dinheiro sob a forma de ca- 
pital a juros, a credito, são elementos que impulsionam a fusão de interesses entre a alta finança e a indústria e que não acontece sem as intervenções políticas dos Estados capitalistas, sobretudo os mais poderosos, como os Estados Unidos e o poder das grandes corporações. Esse contexto é fundamental para compreendermos as narrativas de propagação de crise insustentável da economia, dos mitos dos déficits da previdência e, decifrar o significado das contrarreformas que retira direitos, desconstrui conquistas da classe que vive do trabalho, nos termos de. (ANTUNES, 2001).

3 SEGURIDADE E PREVIDÊNCIA SOCIAL: movimentos de estruturação, tendências e impasses no Brasil contemporâneo

Passamos ao nosso segundo eixo de análise com o interesse de apreender as complexas mediações e particularidades do Brasil, apontando medidas de estruturação e contrarreformas que impactam nas tendências da seguridade social. Destacaremos questões sobre o orçamento da seguridade, alvo de mitos e ataques visando ajustes fiscais e propiciando a mercantilização que invade certos direitos sociais, tornando-os mercadorias que interessam à acumulação de lucros do capital, processo que vem modificando a esfera da proteção social no Brasil e no mundo.

Analisar as particularidades da estruturação e contrarreformas dos direitos sociais no Brasil, especialmente da seguridade social e previdência, requer considerar a contextualidade do Estado e da cultura política, que, seguindo os objetivos da investigação, aqui não podemos aprofundar, mas que devemos ao menos indicar. Destacamos a ocorrência de históricos golpes e ditaduras no Brasil, obstando a construção da cultura democrática e dando margem para ressurgir a política oligárquica em tempos contemporâneos com a persistente conciliação pelo alto, com a permissibilidade das relações pautadas na política do favor, do compadrio com traços paternalistas, clientelistas e patrimonialistas. (COUTO, 2006). País marcado por profundas desigualdades sociais, fruto da perniciosa concentração de renda associada a processos de negação dos direitos sociais arduamente conquistados.

As primeiras marcas de estruturação da seguridade e previdência social brasileira, se deu no contexto do projeto industrial, nacionalista e estatal da engenharia politica getulista. Seguindo Silva (2012), a Previdência Social no Brasil nasce concomitante à estrutu- 
ração do mercado de trabalho (1920-1970) em respostas às lutas dos trabalhadores por maior proteção social. Foi na passagem das Caixas de Aposentadorias e Pensões (CAPs) para a era dos Institutos de Aposentadorias e Pensões (IAPs) que nasce o complexo previdenciário-assistencial, tendo como marco legal a Lei Eloy Chaves. Não foram poucas as tessituras de estruturação da Previdência Social e dos marcos para consolidação de um sistema de seguridade social. Já são fartas as obras que resgatam essa tessitura da seguridade e previdência social, como as análises de Boschetti (2006), Salvador (2010), Silva (2012), e Severiano (2012).

Foi no decorrer da década 1970, na crise da ditadura militar, imersa em dificuldades de diversas ordens e notável dinâmica organizativa dos trabalhadores e da sociedade civil, que conquistamos a CF/1988 e a institucionalidade da seguridade social, com ela, trazendo avanços importantes no marco regulatório fundamentado na linguagem dos direitos.

O conceito de seguridade social e suas políticas constitutivas, com a força de lei, possuem sustentação amparadas na CF/1988 e em legislações sociais especificas, fruto de protagonismos da sociedade civil, ampliou consideráveis conquistas de direitos humanos ${ }^{1}$ pautados em políticas, programas, ações serviços, como importantes direitos sociais da classe trabalhadora. Foi dedicado o Titulo VIII para tratar da Ordem Social, tendo em volta o Capítulo II, artigo194 e 195 que define o conceito de seguridade, princípios e objetivos a serem perseguidos e as fontes de seu financiamento. Compreende um conjunto integrado de ações de iniciativa dos poderes públicos e da sociedade, destinadas a assegurar os direitos relativos à saúde, à previdência e à assistência social. Deve ser organizada com base nos seguintes objetivos:

I. universalidade da cobertura e do atendimento; II. uniformidade e equivalência dos benefícios e serviços às populações urbanas e rurais; III. seletividade e distributividade na prestação dos benefícios e serviços; IV. irredutibilidade do valor dos benefícios; V. equidade na forma de participação no custeio; VI. diversidade da base de financiamento; VII. caráter democrático e descentralizado da administração, mediante gestão quadripartite, com participação dos trabalhadores, dos empregadores, dos aposentados e do Governo nos órgãos colegiados. (BRASIL, 2002, grifo nosso).

A adoção desse conceito e princípios é regado pela orientação do federalismo brasileiro ${ }^{2}$ que impõe a necessidade de ações, projetos, programas e planos nas áreas da saúde, assistência social 
e previdência social, entendidas como gestão pública, de responsabilidade prioritária do Estado, nos níveis federal, estadual, distrital e municipal. Sistema centrado na garantia de direitos universais de saúde, direitos previdenciários derivados e dependentes do trabalho e de contribuição prévia e direitos seletivos de assistência social. Conquistas relevantes, sobretudo pelas definições de fontes de financiamento, instituindo um padrão de financiamento de base diversificada com receitas e despesas integradas em um orçamento único para todos os órgãos e entidades que compõem essa rede de proteção social. Do ponto de vista das diretrizes para a gestão social, a saúde passou a ser política universal com ações e serviços públicos integrando uma rede regionalizada e hierarquizada, constituindo um Sistema Único de Saúde (SUS); o direito à previdência social, embora com a exigência contributiva, por força dos princípios da equidade e universalidade da cobertura, equiparou trabalhador rural e urbano e valores dos direitos previdenciários não inferiores ao salário mínimo. A assistência social vem perseguindo a superação da histórica herança como objeto de barganha populista e clientelista e galgando o lugar de direito social, com legislação própria e política pública organizada em um Sistema Único de Assistência Social (SUAS).

Todavia, sendo produto de disputas de distintos projetos politicos, não ficou imune de paradoxos e ambiguidades. Considerado um texto constitucional avançado do ponto de vista conceitual, mas que enfrenta dificuldades para se materializar, sobretudo, com relação à efetividade dos direitos sociais em face das severas restrições advindas nas décadas seguintes, com a total adesão do Brasil aos ajustes econômicos, direciona o pais num sentido contrário a suas determinações. O maior paradoxo está presente na medida em que o texto constitucional impõe um Estado com essa primazia, porém, a agenda econômica indica a saída do Estado e empurra para a ótica da privatização, da assistencialização e outras estratégias, como a filantropia.

Nesse difícil percurso, nas tramas das lutas sociais, entre conquistas e desafios, a nova institucionalidade da $\mathrm{CF} / 1988$ se impõe. Todavia, já embalada por repetidas e ressuscitadas criticas e crises, sobretudo, vindas dos setores empresariais da economia financeirizada. $\mathrm{O}$ argumento central se localiza em narrativas de vários matizes sobre o custo Brasil, pondo em questão a capacidade do orçamento publico e das responsabilidades do Estado, gerando impasses e dificuldades de efetividade para as politicas de segurida- 
de/ previdência social e para os direitos sociais de um modo geral. Nesse contexto, por um lado, está institucionalizada as conquistas na CF/1988, por outro, seguirá enfrentando impasses e tendências na cena contemporânea, na confluência dos seguidos ajustes estruturais, propiciando paradoxos/dilemas entre o Brasil legal e o Brasil real, gerando o terreno fértil da mercantilização dos direitos sociais, especialmente na seguridade e previdência social que serão alvos de seguidas contrarreformas, favorecendo a apropriação de espaços para o empresariamento da mercadoria, direitos sociais.

Em 2016, aproxima-se de três décadas de existência da Constituição de 1988, e podemos realçar num diálogo profícuo com Mota (2008), Boschetti (2006), Behring (2008), Salvador (2010), Silva (2012) e Severiano (2012), o pressuposto de que a seguridade social representa uma importante conquista, porém, é um projeto inconcluso com lacunas e distâncias entre o instituído legalmente e o vivido na realidade cotidiana. Realçamos a histórica dificuldade da integração das políticas constitutivas realizarem ações intersetoriais, o que remonta ao fato de cada política ter seguido com as suas diretrizes e legislações especificas, em tempos históricos diferentes, sem uma clara articulação entre si. O que pode ser vislumbrado nas Leis especificas, Lei Orgânica da Saúde (Lei no 8.080, de 19 de setembro de 1990); Lei $\mathrm{n}^{\circ}$ 8.212, que trata do custeio da Previdência Social, e Lei $\mathrm{n}^{\circ}$ 8.213, que trata dos Planos de Benefícios da Previdência Social, de 24 de julho de 1991, e, por fim, na Lei ${ }^{\circ} 8.742$, de 7 de dezembro de 1993 com alterações dadas pela Lei ${ }^{\circ} 12.435$, de 6 de julho de 2011, que trata da Assistência Social. Fragilidades que, progressivamente, os governos neoliberais vêm aprofundando; essa segmentação e a falta de articulação entre as áreas ocasionam perdas dessa referência como um sistema integrado e articulado.

Importante realçar o significado contraditório das políticas sociais na sociabilidade erguida sob o comando do capital/do valor. Os sistemas de seguridade e da previdência social representam mecanismos de regulação na sociabilidade capitalista, submetidos às determinações dos processos históricos, econômicos, políticos, sociais e culturais.

Em síntese, na última década do século XX, após o processo de estruturação da seguridade social, ocorre a confluência da adoção de diretrizes neoliberais com seguidos ajustes e contrarreformas do Brasil contemporâneo; paradoxalmente, as conquistas e desafios de 
operacionalidade das determinações jurídico-institucionais da ordem social democrática sofrem constrangimentos e impasses. Podemos afirmar, a ofensiva neoliberal vem corroendo o projeto democrático conquistado pela $\mathrm{CF} / 1988$ e a seguridade social passa a ser o maior alvo de ataques do projeto em curso, atingindo as definições relacionadas ao seu financiamento e orçamento próprio, bem como a gestão pautada na universalidade, equidade e gestão democrática. Ou seja, a proteção social, especialmente a seguridade social sofre determinações da política econômica monetarista que empreende o ajuste fiscal, que promove a privatização (mercantilização dos serviços sociais para os que podem pagar), seletividade/focalização (com políticas pobres para os mais pobres) e descentralização (desconcentração e desresponsabilização do Estado). (BEHRING; BOSCHETTI: 2007; MOTA, 2008). Portanto, os direitos sociais são empurrados para a privatização direta ou indiretamente, transmutando-se em mercadorias e fontes de lucros para o capital. São alvos prioritários, em especial, os direitos à saúde, à educação, à previdência social, o que explica o exponencial crescimento dos fundos de pensões e dos negócios empresariais nessas áreas.

Esse movimento de mudanças e ajustes já foram fortes nos países centrais e chegam, principalmente nas três últimas décadas, nos países periféricos com orientações dos organismos internacionais. As contrarreformas na seguridade social são mecanismos estratégicos de transferências de recursos para a esfera financeira e nessa mesma lógica, ressaltamos o repasse de recursos do fundo público para o pagamento da dívida. Na verdade, assistimos a uma acirrada disputa do fundo público, que em função da desfavorável correlação de forças, tem sido capturado em grande medida para atenção dos interesses do capital portador de juros, que absorve quase metade do orçamento total da União por meio da dívida pública.

Segundo Fattorelli (2016), o sistema da dívida pública se opera como uma engrenagem. $\mathrm{O}$ endividamento público tem se tornado um mecanismo de manipulação e controle do Estado que lança as grandes corporações financeiras para o domínio favorável à atenção dos interesses do grande capital. Os títulos da dívida pública são hoje a espinha dorsal do mercado financeiro e seu volume de transações é gigantesco, remunerados a altas taxas de juros sempre superiores ao crescimento da economia. No Brasil, esses títulos, ao buscarem o financiamento do déficit orçamentário, funcionam como uma bola de neve sobre o endividamento público. E, à medida que 
este avança, tem-se a privatização como prescrição de uma parte do capital produtivo nacional das nações devedoras, sob a forma de aquisição de empresas públicas para permitir a conversão da dívida em títulos de propriedade entregues aos credores. Portanto, a auditoria da divida pública é uma necessidade, pondo em questão valores de grande monta, que são transferidos do orçamento público para o pagamento da dívida, e nesse nicho, não se mexe e não se costuma questionar o quanto de superávits do orçamento publico são destinados para esse fim.

Assim, compreendemos as mediações que pautam as contrarreformas nas políticas constitutivas da seguridade social brasileira no contexto da agenda ortodoxa do neoliberalismo das ultimas décadas, que orientam severos ajustes econômicos. O orçamento da seguridade tem sido alvo de mitos e ataques visando ajustes fiscais em nome da redução do déficit nas contas públicas e da austeridade direcionada, sobretudo, aos direitos e conquistas da classe trabalhadora, sendo um dos impasses e que nos exige decifrar os enigmas envolvidos nas narrativas relacionadas ao déficit da seguridade e previdência social.

São fartos os estudos técnicos comprovando que o orçamento da seguridade é superavitário, se considerarmos o que definem os artigos 194 e 195, do Titulo VIII da CF/1988 que trata da Ordem Social e que define a diversidade da base de financiamento com o orçamento único da seguridade. Seguindo essa lógica, desconstrói-se o mito do déficit da Previdência Social, trazendo a análise para as perspectivas envolvidas no debate do fundo público, da auditoria da dívida pública; assim, passamos a ter convicção de que a previdência tem sim, desvios em seu orçamento, desvinculações de receitas do seu orçamento único, desoneração das contribuições, com seguidas sonegações de grandes devedores e com os parcelamentos em longo prazo de valores de monta de suas dividas ativas. Na verdade, sabemos que o orçamento público é fonte de disputas, representa a riqueza socialmente produzida através das diversas formas de tributações.

Destacamos que não são recentes os seguidos ataques a essa importante premissa do orçamento único da seguridade social com fontes vinculadas e base diversificada. Fruto da confluência e paradoxos já indicados, ao longo dos governos neoliberais, mesmo na era dos governos petistas com o questionado viés neodesenvolvi- 
mentista, esse mito foi propagado dando continuidade à segmentação das fontes diversificadas de suas receitas.

Uma das mais perniciosas medidas de ataque ao orçamento da seguridade é a Desvinculação de parte de suas receitas para utilização alheia ao sistema seguridade. Em 2000, para expressar seu verdadeiro caráter, passou a ser denominado Desvinculação das Receitas da União (DRU). Essa medida permitiu o manejo de até 20\% das receitas de impostos e contribuições para compor o superávit primário e, por consequência, a sua utilização para pagamento dos juros da dívida. (SALVADOR, 2010). Em 2014, a DRU retirou do Orçamento da Seguridade Social R \$ 63,2 bilhões. Emenda Constitucional (EC) $n^{\circ} 87 / 2015$ prorrogou a vigência da DRU, aumentando o percentual de desvinculação de $20 \%$ para $30 \%$. Projeções informam representar um saque no orçamento da seguridade na ordem de 120 bilhões anuais. Considerado um assalto aos recursos da seguridade social. Embora com tantos desvios, dados da Associação Nacional dos Auditores Fiscais da Receita Federal do Brasil (ANFIP) (2015) revelam que historicamente o orçamento da seguridade apresenta saldo financeiro superavitário. Nos últimos três anos, os superávits foram: em 2013 de (R \$ 76,2 bilhões); em 2014 (R \$ 53,8 bilhões) e em 2015 (R \$ 23,9 bilhões).

A DRU é um dos expressivos instrumentos para esvaziar o financiamento da seguridade social e implica dificuldades para a efetividade da seguridade. Como afirma Salvador (2010), a concretização da seguridade social exige a efetivação do orçamento da seguridade conforme preconiza o artigo 195 da $\mathrm{CF} / 1988$, ao definir contribuições sociais exclusivas com diversidade da base de seu financiamento. $\mathrm{O}$ imperativo discurso do déficit da previdência não revela informações alarmantes sobre o patamar de sonegação tributária no Brasil. Estudo do Sindicato Nacional dos Procuradores da Fazenda Nacional (SINPROFAZ) mostra que a sonegação da Previdência em 2015 foi de R $\$ 103$ bilhões.

Em síntese, torna-se fundamental decifrar os enigmas das narrativas do déficit, o discurso ideológico da crise da Previdência Social brasileira, da inviabilidade do sistema de seguridade social público e universal. Na verdade, querem mesmo é disseminar a cultura da crise para justificar as restrições de direitos com as seguidas contrarreformas que vêm descaracterizando a seguridade social brasileira. Fundamental decifrar para intervir com uma visão critica de 
seguridade e suas políticas constitutivas, concebida como um direito e cuja garantia está estritamente ligada à garantia de outros direitos humanos fundamentais.

Em 2016 o Brasil vive momentos difíceis, de muitas tensões, após o processo de impeachment da Presidenta eleita Dilma Roussef, resultado de um complexo e inédito golpe de natureza juridico-politico e midiático contra a democracia brasileira. Temores de toda ordem é o que define a conjuntura atual, após o processo eleitoral de 2014 que não terminou em 2014. Confirmado o afastamento e já estava lançado o Programa do Governo Temer com base no documento Uma ponte para o futuro que define compromissos com uma agenda ortodoxa e agressiva de retirada de direitos. Uma das primeiras medidas tomadas por este Governo, representou uma reestruturação do Estado com impactos diretos no desmonte da seguridade. Trata-se da Reforma Ministerial por meio da publicação da Medida Provisória (MP) $n^{\circ} 726$, de 12 de maio de 2016 que extinguiu e juntou Ministérios; nesse contexto, foi extinto o Ministério do Trabalho e da Previdência Social (MTPS) e a transferência da Autarquia Federal Instituto Nacional do Seguro Social (INSS) para o Ministério do Desenvolvimento Social e Agrário (MDSA). Ou seja, a estrutura da Previdência foi desmantelada, bem como outras alterações que fragilizam as políticas voltadas às minorias. As diretrizes desenvolvidas pelo Ministério da Previdência; a Previc; o Conselho de Recursos e a DATAPREV foram alocadas no Ministério da Fazenda. Lá, sabemos, imperam números e economia de mercado, facilitando a materialização das contrarreformas sob a égide do projeto neoliberal ortodoxo que amplia previdência privada e reduz plano de direitos da previdência social pública.

Impressiona a velocidade da lista de medidas de ataques à estrutura do Estado brasileiro e aos direitos sociais; na seguridade social há propostas de Operações pentes finos com revisões analíticas de direitos já concedidos visando produzir economia e asseverar perdas de direitos, aprofundando o movimento de contrarreformas na Previdência Social, o que nos instiga a indagar sobre a democracia que temos, as tendências da seguridade e o futuro da Previdência Social no Brasil.

Nesse contexto, citado governo prepara cenário propício para fundamentar uma das mais rigorosas contrarreformas da Previdência: trata-se da Proposta de Emenda Constitucional (PEC) $\mathrm{n}^{\circ}$ 
55/2016 (Senado), PEC no 241 (Congresso). Essa PEC visa acrescentar novos artigos ao Ato das Disposições Constitucionais Transitórias (ADCT) e institui o denominado novo regime fiscal no âmbito dos orçamentos fiscal e da seguridade social da União pelo prazo de vinte exercícios financeiros. Esse modelo inverte a lógica constitucional, pois onde há obrigação de gastos mínimos haverá um teto e um máximo de gasto que serão corrigidos anualmente pelo índice da inflação. Rigorosa proposta de mudança constitucional desconstitui as bases do modelo de cidadania conquistado em 1988 e limita a capacidade estatal de agir em prol da construção de um modelo de desenvolvimento, com distribuição de renda. Enquanto isso, são inúmeras as abordagens do mercado já incentivando os trabalhadores a constituírem previdências privadas.

\section{A PREVIDÊNCIA SOCIAL E AS CONTRARREFORMAS:} tendências e propostas de retirada de direitos no contexto da democracia em questão

Por fim, passamos ao terceiro eixo de análise, cujas análises, até aqui, apontam que a previdência social é uma política de seguridade, direito social, todavia, tem sido alvo de seguidas contrarreformas operadas no Brasil contemporâneo. Daremos, nessa seção, destaque para as propostas veiculadas no Governo Temer, talvez uma das mais severas contrarreformas que restringirá mais direitos sociais previdenciários; se aprovada, afetará tanto o Regimes Geral como o Regime Jurídico dos servidores públicos. Tem sido relevante o vasto volume de estudos e publicações com o intuito de desmistificar esse falso déficit propagado, da previdência, informando as propostas de contrarreformas na previdência e que giram em torno de sete itens, quais sejam: 1) financiamento da previdência social: receitas, renúncias e recuperação de créditos; 2) demografia e idade mínima das aposentadorias; 3 ) diferença de regras entre homens e mulheres; 4) regras das pensões por morte; 5) previdência rural: financiamento e regras de acesso; 6) regimes próprios de previdência e 7) convergência dos sistemas previdenciários.

Destacamos que o sistema previdenciário brasileiro, após a Carta Magna, está instituído basicamente sobre três pilares: a Previdência Social básica, gerida pelo INSS-autarquia pública federal e constituída pelo Regime Geral de Previdência Social (RGPS) obrigatório e de repartição simples com solidariedade entre gera- 
ções com tetos salariais mínimos e máximos; os Regimes Próprios de Previdência dos Servidores Públicos e militares (RPPS), geridos pelos gestores públicos dos estados e munícipios, que pressupõem a tarefa de constituirem seus fundos de previdência e, por fim, o Regime de Previdência Complementar Privado (RPCP) na modalidade aberto ou fechado, financiado pelo sistema de capitalização, lócus de desenvolvimento das previdências complementares/ fundos de pensão que se propõem a complementar o regime de previdência oficial. (SEVERIANO, 2012).

A Previdência Social tem como principais objetivos evitar a queda brusca de renda na velhice, garantir renda ao segurado no caso de alguma contingência (acidente, gravidez, doença, velhice, entre outros) e atuar na redução da pobreza e movimentação da economia via consumo. A primeira função ocorre quando o segurado do sistema previdenciário chega à velhice e busca o direito à aposentadoria. A segunda função existe para proteção do trabalhador ou trabalhadora que, por motivo de doença, acidente, gravidez ou outros, enfrente a impossibilidade permanente ou temporária de receber remuneração do trabalho. A função de redução da pobreza e movimentação da economia via consumo é uma importante consequência dos sistemas de proteção social que transfere renda, via pagamento de um valor mínimo e máximo (salário mínimo e teto previdenciário), em forma de direitos sociais previdenciários e assistenciais. Tem sido importante mecanismo de dinamização da economia na área urbana e rural e vem incidindo em menores índices de pobreza no Brasil.

No intuito de contribuir com reflexões sobre a temática, registramos abaixo quadro-síntese com as principais contrarreformas operadas no Brasil contemporâneo, apontando tendências/impasses/ propostas que estão sendo veiculadas, que, em se confirmando, representará uma profunda precarização dos direitos previdenciários e desmontará a estrutura constitucional da política de previdência publica no Brasil. Importante destacar que a base de sustentação para tamanho desmonte está em plena tramitação de aprovação no Senado, com o PEC n ${ }^{\circ}$ 55/2016 (Senado) e PEC no 241 (Congresso). Também denominada pelos movimentos sociais de luta e resistência - PEC da morte, PEC da desigualdade.

Quadro 1 - Quadro síntese de reformas/contrarreformas operadas no Brasil contemporâneo: tendências/projeções no contexto da democracia em questão 


\begin{tabular}{|c|c|}
\hline GOVERNOS & PRINCIPAIS CONTRARREFORMAS/PROPOSTAS \\
\hline $\begin{array}{l}\text { Governo } \\
\text { Fernando } \\
\text { Henrique } \\
\text { Cardoso (1995- } \\
\text { 2002) }\end{array}$ & $\begin{array}{l}\text { Emenda Constitucional } n^{0} 20 \text { de 1998: Essa Emenda significou uma das mais } \\
\text { expressivas contrarreformas, atingindo especialmente o Regime Geral de } \\
\text { Previdência Social. Como principais alterações: extingue o critério de tempo de } \\
\text { serviço e institui a referência apenas do tempo de contribuição; adoção do fator } \\
\text { previdenciário para as aposentadorias por tempo de contribuição e institui o } \\
\text { princípio do equilíbrio financeiro e atuarial na política de previdência, acentuando } \\
\text { o seu caráter de seguro. }\end{array}$ \\
\hline $\begin{array}{l}\text { Governo Lula } \\
(2003-2010)\end{array}$ & $\begin{array}{l}\text { Emenda Constitucional } n^{0} 41 \text { e a Emenda paralela } n^{0} \text { 47: redesenham a } \\
\text { previdência social do servidor público, com retração de direitos, que impõe idade } \\
\text { mínima associada a tempo de contribuição, postergando as aposentadorias dos } \\
\text { servidores públicos. Institui a previdência complementar com a criação do maior } \\
\text { Fundo de pensão- FUNPRESP; } \\
\text { Institui a Receita Federal do Brasil (2004) e retira do INSS a finalidade da } \\
\text { arrecadação e fiscalização das receitas da seguridade; Institui a Superintendência } \\
\text { de Previdência Complementar- PREVIC. } \\
\text { Inclusão do Microempreendedor Individual/ Facultativo Baixa Renda. } \\
\text { Pelo Decreto } 6.042 \text { de } 12 / 02 / 2007 \text { - institui o Plano Simplificado de Previdência } \\
\text { Social. Institui o Ministério do Desenvolvimento Social- MDS, com significativa } \\
\text { ampliação de programas de transferência de renda através do programa bolsa } \\
\text { família; Institui o Estatuto da Pessoa Idosa e amplia o BPC para famílias com mais } \\
\text { de um idoso na composição da renda. }\end{array}$ \\
\hline $\begin{array}{l}\text { Governo DILMA } \\
\text { (2011 -2014 }\end{array}$ & $\begin{array}{l}\text { Destaque para as Medidas Provisórias Nos } 664 \text { de } 2014 \text {, transformadas nas } \\
\text { Leis } 13.135 / 2015 \text { e } 13.134 / 2015 \text { - o que também significou uma contrarreforma } \\
\text { com alterações na pensão por morte, auxílio-reclusão e no auxilio-doença. As } \\
\text { alterações modificaram o RGPS e o regime de previdência dos servidores federais. } \\
\text { As principais alterações versam sobre a exigência de carência para concessão } \\
\text { do benefício, introdução de tempo mínimo de união ou casamento e de tempo } \\
\text { máximo de duração do benefício, considerando critério etário. Exclusivamente para } \\
\text { o RGPS, também houve mudança no cálculo do valor do benefício. Recente Lei } \\
13.183 / 2015 \text { instituiu a regra } 85 / 95 \text { progressiva, com isso o sistema previdenciário } \\
\text { brasileiro já passou a ter a inserção da idade mínima de forma tácita, limitando o } \\
\text { acesso ao benefício (85/95 - 90/100) ou a redução drástica da renda mensal para } \\
\text { aqueles que querem se aposentar mais cedo (Fator Previdenciário). }\end{array}$ \\
\hline
\end{tabular}




\begin{tabular}{|c|c|}
\hline $\begin{array}{l}\text { Principais } \\
\text { e severas } \\
\text { propostas de } \\
\text { contrarreformas } \\
\text { na Previdência } \\
\text { /Governo } \\
\text { Provisório } \\
\text { TEMER/2016 } \\
\text { Fontes: cartilha } \\
\text { Sindicato dos } \\
\text { bancários e } \\
\text { Frente Brasil } \\
\text { Popular e em } \\
\text { matérias de } \\
\text { jornais de grande } \\
\text { circulação. } \\
\text { Importante } \\
\text { destacar que se } \\
\text { trata de proposta } \\
\text { não formalizada, } \\
\text { o que poderá } \\
\text { ter alterações, } \\
\text { sobretudo, } \\
\text { considerando } \\
\text { um tema } \\
\text { que mobiliza } \\
\text { bastante a } \\
\text { classe que vive } \\
\text { do trabalho. }\end{array}$ & $\begin{array}{l}\text { Elevação da idade mínima: propõe fixar uma idade mínima de } 65 \text { anos para } \\
\text { homens e mulheres, unificando a regra para os regimes - geral e dos servidores, } \\
\text { chegando a } 70 \text { anos para as novas gerações. Hoje a legislação está assim: } 65 / 60 \\
\text { anos homens/mulheres, associado ao acúmulo de } 15 \text { anos de contribuição. } \\
\text { Propõem elevar contribuições, neste caso, dos atuais } 15 \text { anos para } 20 \text { anos. } \\
\text { Trabalhadores ativos serão atingidos com regras de transição e direito garantido } \\
\text { para quem já implementou. Passando a vigorar, seremos campeões mundiais em } \\
\text { exigências para aposentadoria. } \\
\text { Equiparação de idade mínima de } 65 \text { anos para homens e mulheres: hoje, as } \\
\text { mulheres se aposentam com redutor de } 5 \text { anos em relação aos homens; a diferença } \\
\text { atende ao principio da equidade ante as condições desfavoráveis das mulheres. A } \\
\text { proposta pretende unificar em } 65 \text { anos a idade mínima para os dois sexos. A nova } \\
\text { regra afetará integralmente as mulheres com até } 45 \text { anos. Acima dessa idade, } \\
\text { valerá a regra de transição. Assim, a igualdade ocorrerá gradualmente, ao longo } \\
\text { de } 20 \text { anos. } \\
\text { Idade mínima de } 65 \text { anos para trabalhadores urbanos e rurais: desconsideram-se } \\
\text { as enormes heterogeneidades da zona rural brasileira. } \\
\text { Pensão por morte }\end{array}$ \\
\hline
\end{tabular}

Fonte: Elaborado pela autora, com base em Severiano (2016).

\section{CONCLUSÃo}

Ao longo dos governos neoliberais vêm se somando contrarreformas que subtraem direitos na seguridade/previdência social. A proposta que tem sido publicizada no Governo Temer mostra-se severa para a classe trabalhadora, precarizando o atual quadro de direitos da previdência social pública brasileira, fruto das conquistas da CF/1988, cujas regras, para muitos trabalhadores, já são inacessíveis. Como analisamos neste ensaio, são múltiplas as determinações e exige decifrar recíprocas relações do capitalismo sob a hegemonia 
da financeirização da riqueza. A seguridade social brasileira, transformada em objeto de contrarreformas, aprofunda a precarização dos direitos sociais, sob duplo movimento sincronizado de mercantilização de direitos, sobretudo na saúde, previdência, educação e acesso seletivo e focalizado na política de assistência social. No Brasil, três processos articulados são confluentes: as conquistas democráticas e direitos sociais na Constituição/1988, ciclos de ajustes e contrarreformas à ordem do capital financeirizado, e o mais recente fenômeno denominado golpe parlamentar-jurídico e midiático no contexto da democracia em questão.

Destacamos que durante o estudo, registramos diversas alternativas possíveis, para além das contrarreformas e que certamente trariam oportunidades de enfrentar os desafios da seguridade e previdência social ${ }^{3}$. Outrossim, exige outra direção de estratégias articuladas com o compromisso político de fortalecer a proteção social da classe que vive do trabalho, embora, nos limites do capital. Passa por opções econômicas e políticas no enfrentamento da divida públi$\mathrm{ca}$, aderindo à proposta de auditoria da dívida e redução da taxa de juros de títulos da dívida. Do ponto de vista estrutural, fundamental crescimento econômico associado ao desenvolvimento social, fortalecendo a intervenção do Estado e priorizando a geração de emprego e renda. Sobre o fundo público, estabelecer um orçamento público com controle social e política tributária justa e democrática, promovendo a reforma tributária com justa taxação dos latifúndios e grandes fortunas. Em suma, ampliar, e não, reduzir, a política de seguridade social/previdência, políticas com capacidades de ampliar a redistribuição da riqueza socialmente produzida com capacidade para reduzir desigualdades e não somente combate à pobreza absoluta.

\section{REFERÊNCIAS}

ANTUNES, R. Os sentidos do trabalho: ensaio sobre a afirmação e a negação do trabalho. 4. ed. São Paulo: Boitempo, 2001.

ASSOCIAÇÃO NACIONAL DOS AUDITORES FISCAIS DA RECEITA FEDERAL DO BRASIL. Seguridade Social e Tributação, Brasília, DF, jun./set. 2015.

BECKER, H. S. Segredos e truques da pesquisa. Tradução de Maria Luiza X. de A. Borges. Rio de Janeiro: Jorge Zahar, 2007. 
BEHRING, E. R. Brasil em contra-reforma: desconstrução do Estado e perda de direitos. 2. ed. São Paulo: Cortez, 2008.

; BOSCHETTI, I. Política Social: fundamentos e história. 3. ed. São Paulo: Cortez, 2007.

BOSCHETTI, I. Seguridade social e trabalho: paradoxos na construção das políticas de previdência e assistência social no Brasil. Brasília: Letras Livres; UnB, 2006.

BRASIL. Constituição da República Federativa do Brasil: promulgada em 05 de outubro de 1988: atualizada até a Emenda Constitucional n ${ }^{\circ}$ 35 de 20 de dezembro de 2001. 29. ed. São Paulo: Saraiva, 2002.

CHESNAIS, F. A finança mundializada. São Paulo: Boitempo, 2005.

CONSELHO FEDERAL DE SERVIÇO SOCIAL. Carta de Maceió - seguridade social pública: é possível! In: ENCONTRO NACIONAL CFESS/CRESS, 29., 2000, Maceió. Arquivos... Maceió, 2000. Disponível em:<http://www.cfess.org.br/arquivos/ CARTADEMACEIO.pdf $>$. Acesso em: 19 jun. 2016.

COUTO, B. R. O direito social e a assistência social na sociedade brasileira: uma equação possível? 2. ed. São Paulo: Cortez, 2006

FATTORELLI, Maria Lucia. Dívida pública, transparência fiscal e auditoria cidadã. In: AUDITORIA CIDADÃ DA DÍVIDA, 2016, Belo Horizonte. Arquivos... Belo Horizonte, 2016. Disponível em:<www. auditoriacidada.org.br>. Acesso em: 19 jun. 2016.

MAGALHÃES, A. O que nos ameaça é um grave retrocesso neoliberal. Calle2, [S. 1.], 2016. Entrevista com Luiz Carlos Bresser Pereira. Disponível em: <http://calle2.com/o-que-nos-ameaca-e-umgrave-retrocesso-neoliberal $>$. Acesso em: 19 jun. 2016.

MOTA, A.E. S. da. O mito da assistência social: ensaios sobre Estado, política e sociedade. 2. ed. rev. e ampl. São Paulo: Cortez, 2008.

OLIVEIRA, F. de. Os direitos do antivalor: a economia política da hegemonia imperfeita. Petrópolis, RJ: Vozes, 1998.

SALVADOR, E. Fundo público e seguridade social no Brasil. São Paulo: Cortez, 2010.

; SILVA, M. L. L. Fundo público e as medidas provisórias nos 664 e 665: a contrarreforma da previdência em curso. Revista Política Social e Desenvolvimento, [S. 1.], v. 19, p. 24-47, 2015.

SEVERIANO. E. M. O. Previdência Social e dilemas da seguridade no Brasil contemporâneo: trajetórias de "sujeitos de direitos" entre 
o trabalho e o adoecimento. 2012. Tese (Doutorado) -Universidade Federal do Ceará, Fortaleza, 2012.

SILVA, M. L. L. da. Previdência Social no Brasil: (des)estruturação do trabalho e condições para sua universalização. São Paulo: Cortez, 2012.

SOUZA, A. S. de P. e. A origem do Federalismo brasileiro. Revista Jus Navigandi, Teresina, ano 15, n. 2642, set. 2010. Disponível em: $<$ https://jus.com.br/artigos/17486>. Acesso em: 19 jun. 2016.

\section{NOTAS}

1 Alio-me a concepção de direitos humanos defendida pelo Conjunto CFESS-CRESS (Documento CFESS manifesta, set/2012).

2 Sobre o federalismo na Constituição de 1988 (Disponível: http://jus.com.br/ artigos/17486/a-origem-do-federalismo-brasileiro\#ixzz3UvUNWNjJ).

3 Sobre sonegação (Disponível em: $<$ http://www.quantocustaobrasil.com.br/artigospdf/sinprofaz_indicador_sonegacao-28-06-2016.pdf $>$ ) e excelente produções sobre propostas reforma da Previdência Social (Disponível em: $<$ http://www. frenteparlamentardaprevidencia.org/estudos/ $>$ ) 